\title{
ROLE OF HEAT TREATMENT AND EVALUATION OF MECHANICAL PROPERTIES OF AI LM13 REINFORCED WITH HEMATITE
}

\author{
Rajesh.T.R ${ }^{1}$, Meghani Molies Reddy ${ }^{2}$, Batluri Tilak Chandra ${ }^{3}$, Sunil Kumar.M ${ }^{4}$ \\ ${ }^{I}$ Assistant Professor, Mechanical Engineering, GCEM, Bangalore, Karnataka, India \\ ${ }^{2}$ Assistant Professor, Mechanical Engineering, SIET Tumakuru, Karnataka, India \\ ${ }^{3}$ Assistant Professor, Mechanical Engineering, SSIT Tumakuru, Karnataka, India \\ ${ }^{4}$ Assistant Professor, Mechanical Engineering, PNSIT, Bangalore, Karnataka, India
}

\begin{abstract}
Aluminium alloys are usually used in automotive and aerospace industry due to their acceptable mechanical property and very low down density, most excellent rust conflict and frictional wear ,short thermal coefficient of extension as compare with respected to stereotypical metallic materials and different alloys.The amazing motorized properties of aluminium alloys and reasonably low down manufacture cost brand name as a especially desirable applicant used for a range of diversity of application concurrently from methodical and technological view. The tendency include in designing metal matrix material composites is to mutually in the appropriate attribute metals and ceramics. Present work is cantered on the study of behaviour of in aluminium alloys (alluminiumLM13) with hematite (Fe2O3) composite manufactured by the stir casting method, diverse proportion of reinforcement is utilize. Tensile test, compression test, hardness test, was complete on the model specimen produced by the strincasting procedure.
\end{abstract}

Keywords: Al LM13, Hematite, Tensile, Compression and Hardness Test, Stir Casting.

\section{INTRODUCTION}

Materials which are used in present days in automobile, aerospace are composites instead of metallic materials like bone, natural fibres, etc as they either natural or manufactured by different methods. A typical composites are the most growing and suited engineering materials now to people .To move forward in the area of material science and metallurgy has given consanguineous to these attractive and amazing materials.

Composites are heterogeneous in nature designed by the foregathering of two or more components with filler and a compactable matrix If the mixing occurs on a microscopic scale, the recent is then known as alloy or polymers usually, a composite materials is composition of reinforcement phase such as fibres, flakes, particles and fillers securely surrounded in a matrix of metals, ceramics, polymers. The matrix retains the reinforcement to form the wanted shape. the entire property of the matrix are improved by the strengthening .while designed correctly the innovative mixed material shows good strength and other unique materials metal matrix are largely used in so many applications embarrass automotive and parts of aircraft, consumption product and electronic product, these can be manufactured by typical or stereotypical methods .such as stir casting, injection moulding, powder metallurgy to create a parts for automobile and aerospace applications.

\subsection{Over View of Metal Matrix}

Metal matrix composites similar compositions it contains of a minimum two bodily and chemically segment of distinct, it's only appropriate for it to deliver the dispersed properties and specific phases are not available. Usually there exists a two phases particulate or fibrous segment in a metallic matrix for ex; AL2O3 copper matrix reinforced with fiber for excellent leading magnets. Aluminum alloys reinforced with Sic particles used in thermal management, aerospace and automobile applications.

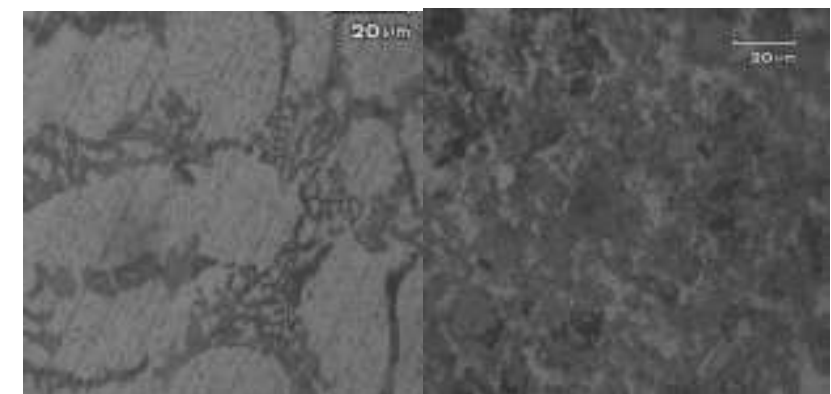

Fig 1.1 As caste 12\%Hematite Fig 1.2 AlLM13-Heattreated

\section{LITERATURE SURVEY}

Phanibhushana.M.V, Dr.C.N Chandrappa,.[1] at present analysis, uncontaminated aluminium Al6061 -2, 4, 6 and 8\% (by weight)hematite (ferrous oxide Fe2o3) composites were manufactured by the stir casting process.Micro structure analysis is made on the visual microscopy, in that they identified a homo allocation of hematite particle in the metal matrix phase and also obtained a high-quality bounding $\mathrm{b} / \mathrm{w}$ metal matrix and hematite. The hardness of the Al6061hematite composites increased by $30 \%$ in the reinforcement of hematite and density of the composites also improved with raise in the reinforcement of the hematite than the pure 
aluminium Al6061and tensile potency of composites is enhanced by $25 \%$ when $8 \%$ of hematite is reinforced to the base Al6061, increasing of mechanical properties were viewed with rising amount of in a stir casting process.

S.Karunakara, P.Dinesh, at ., 2014 [2] In this investigational learning, Al base hematite particle reinforced composite material was manufactured by powder metallurgy. The compression strength of the hybrid, stretching strength of the composite and hardness at irregular compaction pressure and different temperature were studied. The result of the tests exposed that hematite particles can be effectively used as a reinforcement material and it does not deteriorate the property. The ever-increasing hematite particles percentage and high compaction pressure resulted in high density of the compact. There by ever-increasing compression strength of composite, tensile strength of composite and hardness of component. Sintering play a most important role having straight effect on physical properties of the component with changing sintering temperature, maximum compression strength of $270 \mathrm{Mpa}$,tensile strength of $187 \mathrm{Mpa}$ and hardness about $69 \mathrm{BHN}$ was attain for $8 \%$ hematite particles at sintering temperature $5000 \mathrm{c}$ and compaction pressure 400Mpa .

S.Ezhil vannan, S.Paual vizhian,at.,2014[3] at present investigation. Efforts are made to study the microstructure properties of a cast $\mathrm{Al}$ alloy 7075 with short basalt fibre reinforcement in the percentage varies from 2.5 to $10 \%$ in the steps of $2.5 \%$ and fabrication using campo-casting technique.

\subsection{Summary of Literature Review}

In the current exploration, the potency of compound AlLM13-Hematite is calculated by the proportion of strengthening and compare with the impotency of tempered sampling with the same composition and calculate the mechanical strength of the compound accounting microstructure examination using visual microscopy of the case made-up with hematite particulates of 150 microns in diverse composition such as $3 \%, 6 \%, 9 \%, 12 \%$ and $15 \%$ by Means of stir cast manner.

\subsection{Objectives}

1. To prepare the economical MMC material by taking $\mathrm{Al}$ LM13 alloy with metal matrix particulate like Hematite as reinforced phase using stir casting method.

2. To examine the micro structural characteristics of the as cast composite material.

3. To made the heat treatment to the cast composite materials and comparing with as cast composite materials.

The Tensile strength, compression strength \& Hardness of the cast composite materials are identified by preparing the specimen by ASTM standards

\subsection{Materials and Methods}

\subsubsection{Materials}

For the present investigation purpose the aluminium used for preparing of metal matrix alloys was pure LM13 and it was purchased from fen fee metallurgy Bangalore, Karnataka, India and hematite powder was purchased by Hindustan minerals Mangalore and magnesium was commercial available. The chemical properties of AlLM13 and hematite are as mentioned in table 3.1 and 3.2 respectively

Table 3.1 Chemical composition of LM13

\begin{tabular}{|l|l|l|l|l|l|l|l|l|l|l|}
\hline Chemical composition & $\mathrm{Cu}$ & $\mathrm{Mg}$ & $\mathrm{Si}$ & $\mathrm{Fe}$ & $\mathrm{Ma}$ & $\mathrm{Ni}$ & $\mathrm{Zn}$ & $\mathrm{Pb}$ & $\mathrm{Tin}$ & $\mathrm{Ti}$ \\
\hline percentage & 1.3 & 1.5 & 13.0 & 0.8 & 0.5 & 3.0 & 0.1 & 0.1 & 0.1 & 0.2 \\
\hline
\end{tabular}

Table 3.2 Chemical composition of Hematite

\begin{tabular}{|l|l|l|l|l|l|l|l|l|}
\hline Chemical composition & $\mathrm{Fe}$ & $\mathrm{Mn}$ & $\mathrm{Mg}$ & $\mathrm{Ti}$ & $\mathrm{Al}$ & $\mathrm{Ca}$ & $\mathrm{Si}$ & Loss of ignition \\
\hline Hematite & 81.13 & 0.14 & 1.55 & 0.03 & 0.57 & 4.8 & 4.2 & 5.82 \\
\hline
\end{tabular}

\subsection{Experimental Work}

The fluid state method is also called as stir casting manner, be mainly utilized intended for the fabrication of composite substances in that a reinforcing stage is heterogeneously mixes with a molten medium metal by the use of a automatic stirring after this the fluid composite materials is afterwards made by means stereotypical manufacturing techniques it might be process by stereotypical metal shaping techniques.

1. Melting the aluminum LM 13 alloy.

2. Arranged and pre heating of the reinforcements.

3. De- gassing and removal of slag.

4. Combined the metal and reinforcing material.

5. Collecting the molten metal and reinforcement and mix to the die.

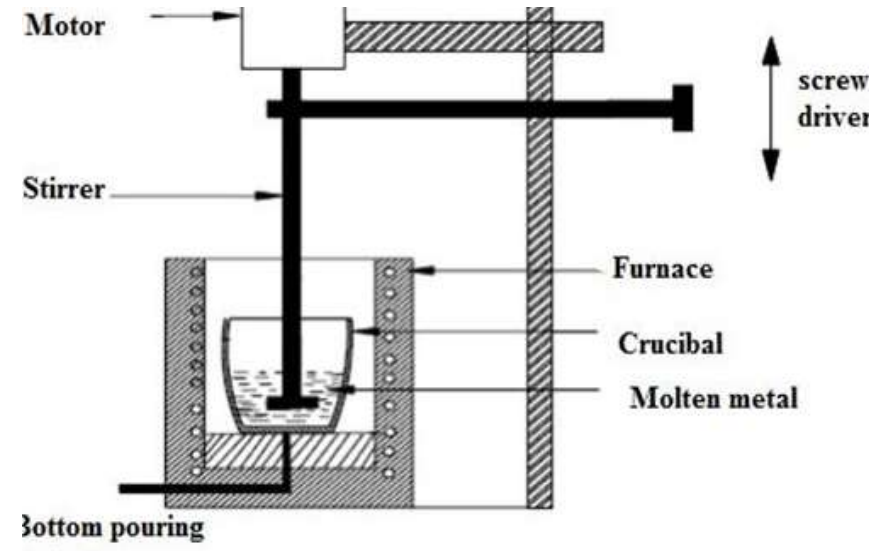

vstem 
For melting the alloy an electric arc furnace is mainly used. The container heater and is Heated electrically at 3 phase resistance of $12.55 \mathrm{~kW}$ capabilities. The heater range is $1200^{\circ} \mathrm{C}$ with precision of $+/-1.5 \mathrm{C}$. The aluminum alloy which was earlier melted. The aluminum LM 13 is cut to small pieces rendering to the essential and additional to the pre heated vessel. Once the vessel has been changed, switch on the heater to $750^{\circ} \mathrm{C}$ temperature.

\subsection{Heat Treatment}

This involves tempering of Aluminum alloy to a desired temperature for calculated time.The alloying elements become solid solution and form homogenous phase. The mechanical factors which affect the final properties of alloy are soaking temperature, time and cooling rate.

The type of treatment process used is T6 method. Commonly applied T6 Heat Treatment Process:

1. Solutionising :Keep at furnace in $525^{\circ}$ Celsius for $8 \mathrm{hrs}$.

2. Quenching : Sudden Quenching Water at $30^{\circ} \mathrm{C}$.

3. Natural Aging : Upto 5 Hrs

4. Precipitation : Keep in furnace at $165^{\circ} \mathrm{C}$ for $8 \mathrm{hrs}$.

5. Hardness to be achieved between $80-100 \mathrm{BHN}$

\section{Experimental Procedure}

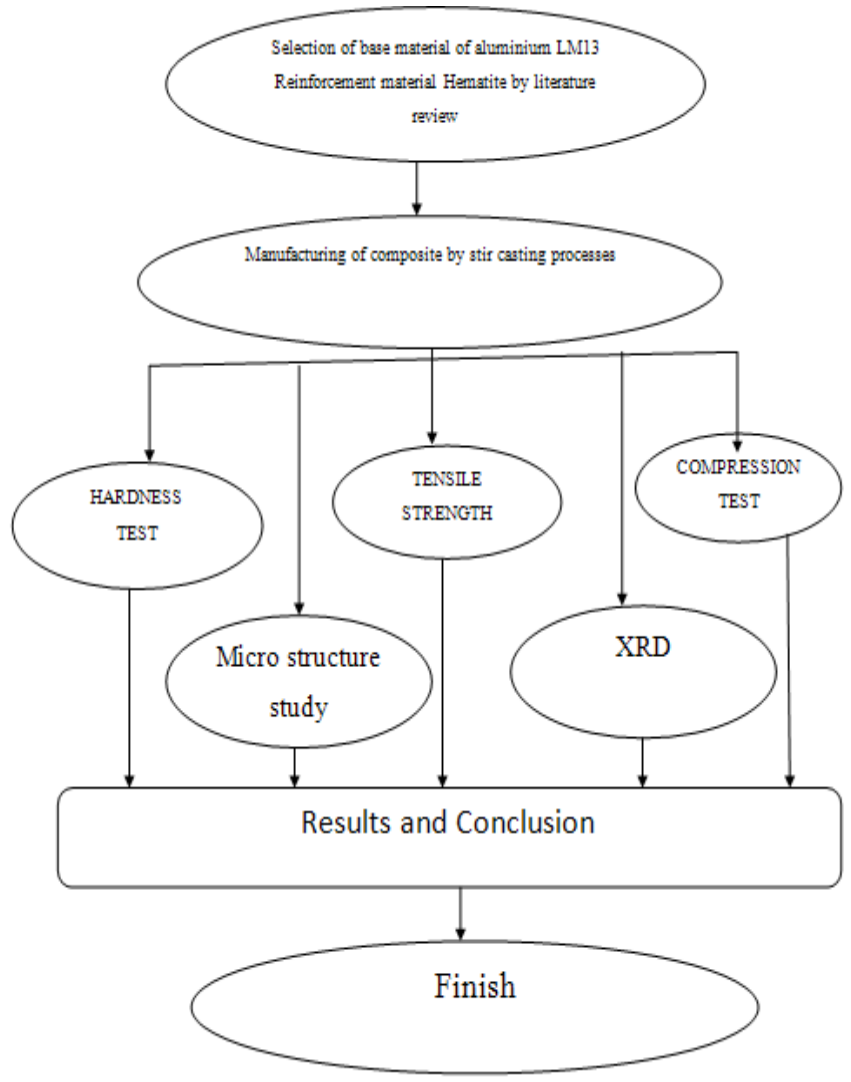

\subsection{Hardness Test}

Hardness is usually thought about as a opposition to penetration. The material will be stronger .Hardness is straightforwardly with the material mechanical properties. Agent referring hardness includes grain size, grain shape, structure of the grains, etc. Usually hardness increments the ultimate tensile strength and yield strength, because of this hardness test of the composite material is more important .The common method of testing includes Brinell, Rock well and Vickers hardness test.

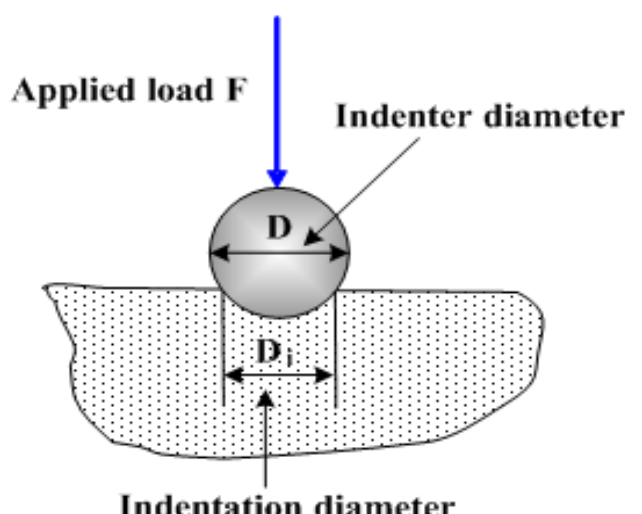

Indentation diameter

Fig 3.5 Brinell hardness testing

\subsection{Tensile Test}

Tensile strength is the function of a fabric or substance to endure a pull (tensile) force. It is habitually deliberate in units of force per cross-sectional area. This is important concept in material science, mechanical and structural engineering. The ability to resist failure under tensile stress is the most important and widely measured properties of materials used in structural applications. Tensile strength is important in the use of brittle materials more than ductile materials.

\subsubsection{Yield Strength}

Yield strength of metals is expressed in materials science and engineering field as the stress at which a material starts to warp plastically. Before to the yield point the material will warp elastically and will come back to its initial shape when the applied stress is realized. If the yield point is starts, some amount of the deformation will be permanent and nonreversible. In the three-dimensional volume of the principal stresses ( ), an unbounded number of yield points together forms a yield surface.

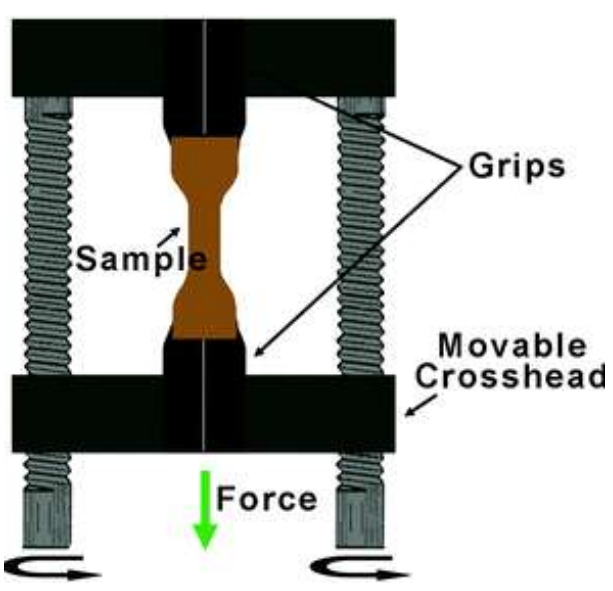

Fig 3.6.1 Tensile test on UTM 


\subsection{Compression Test}

The compressive impotency is the material or specimen to endure loads offers to decrease the size. It may be identified by drawing applied force vs change in length and diameter in a universal testing machine. Few materials are broken at their compressive capability limit; others distort invariably, so a considering quantity of change in shape might be taken as the boundary for compressive load. Compressive capability is a key factor for design of configurations.

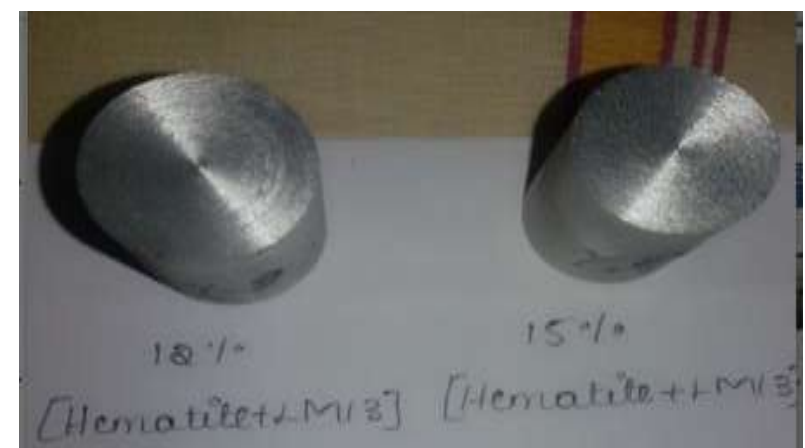

Fig 3.7 Compression Test component

\section{RESULTS AND DISCUSSION}

\subsection{Hardness Test}

The graph shows hardness v/s ageing period, results for LM13-Hematite particulate composite for heat treated and ice quenched specimen
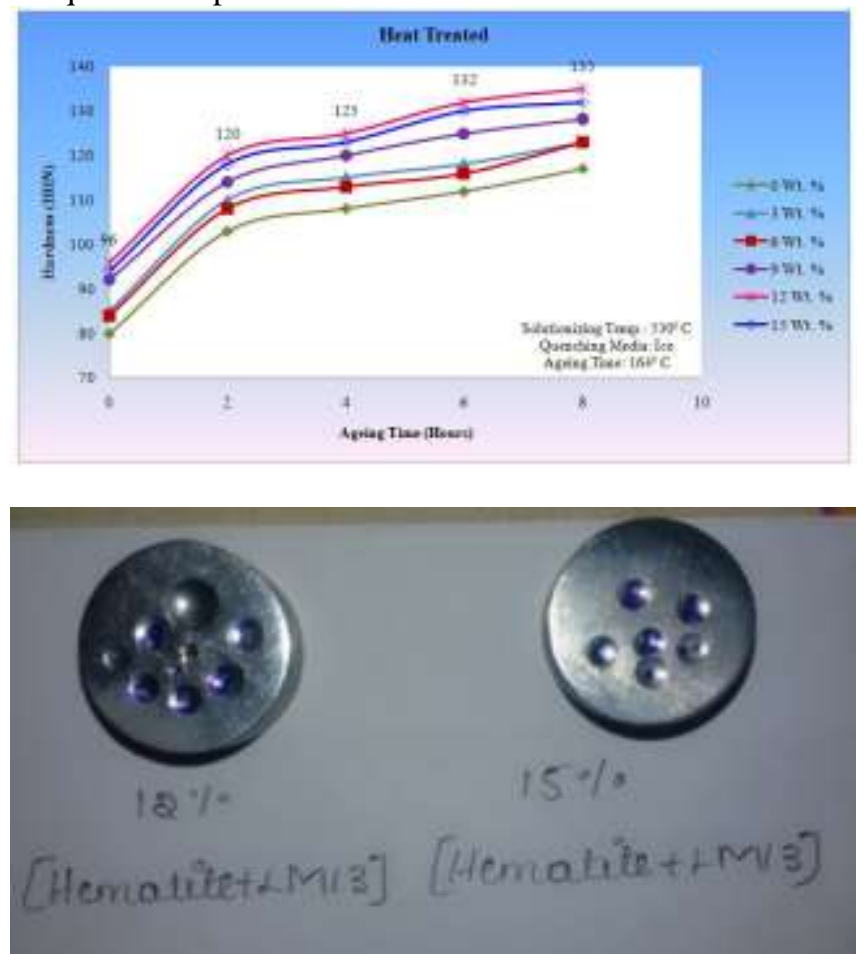

Fig 4.1 Hardness indentation on the component

\subsection{Tensile Test}

The graph shows tensile strength v/s composition, results for LM13-Hematite particulate composite for heat treated and ice quenched specimen

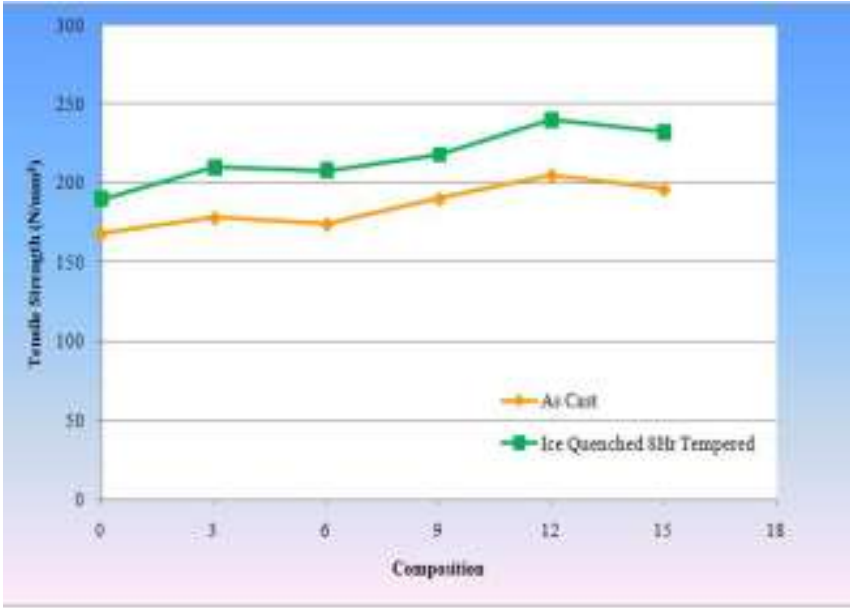

Fig 4.2.1 Tensile power of as cast and ice quenched $8 \mathrm{Hr}$ tempered Al LM13-Hematite

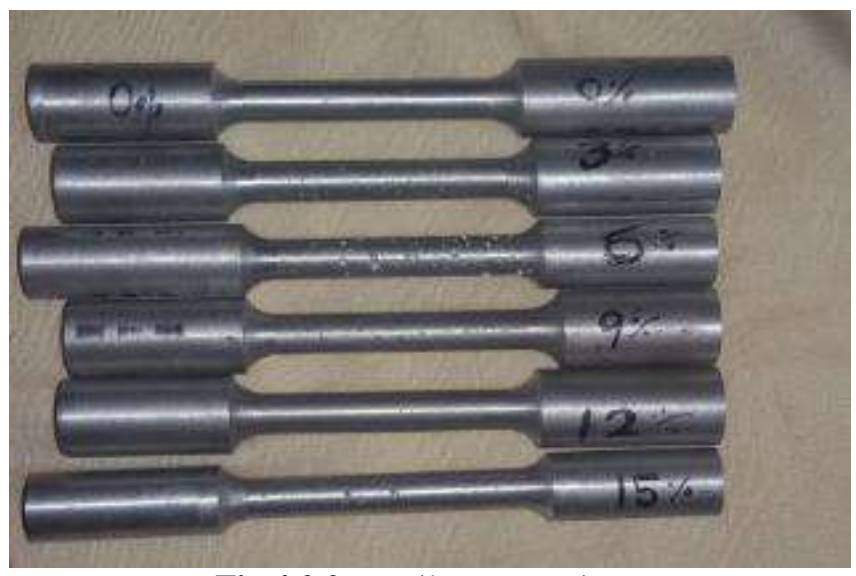

Fig 4.2.2 Tensile test specimen

Table 4.2 Compression of as cast and ice quenched Tensile

\begin{tabular}{|l|l|l|}
\hline $\begin{array}{l}\text { Composition of } \\
\text { Hematite \% }\end{array}$ & $\begin{array}{l}\text { As cast } \\
\text { Tensile } \\
\text { strength } \\
\text { in } \\
\text { N/mm }\end{array}$ & $\begin{array}{l}\text { Ice Quenched } \\
\text { 8Hr Tempered } \\
\text { Tensile strength } \\
\text { in N/mm }\end{array}$ \\
\hline 0 & 168 & 190 \\
\hline 3 & 178 & 210 \\
\hline 6 & 174 & 208 \\
\hline 9 & 190 & 218 \\
\hline 12 & 205 & 240 \\
\hline 15 & 196 & 232 \\
\hline
\end{tabular}

\subsection{Compression Test}

The graph shows tensile strength v/s composition, results for LM13-Hematite particulate composite for heat treated and ice quenched specimen 


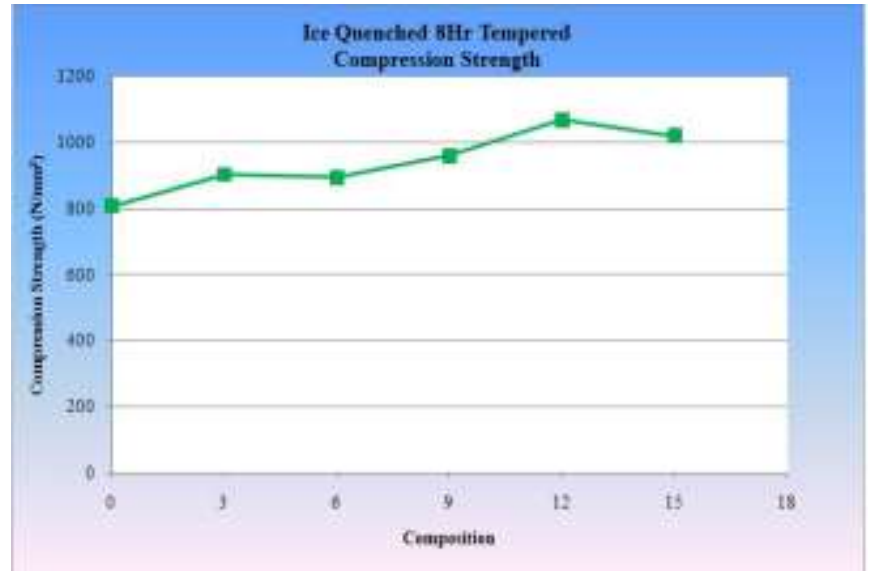

Fig 4.3.1 Compression strength of Ice Quenched 8Hr tempered AlLM13-Hematite

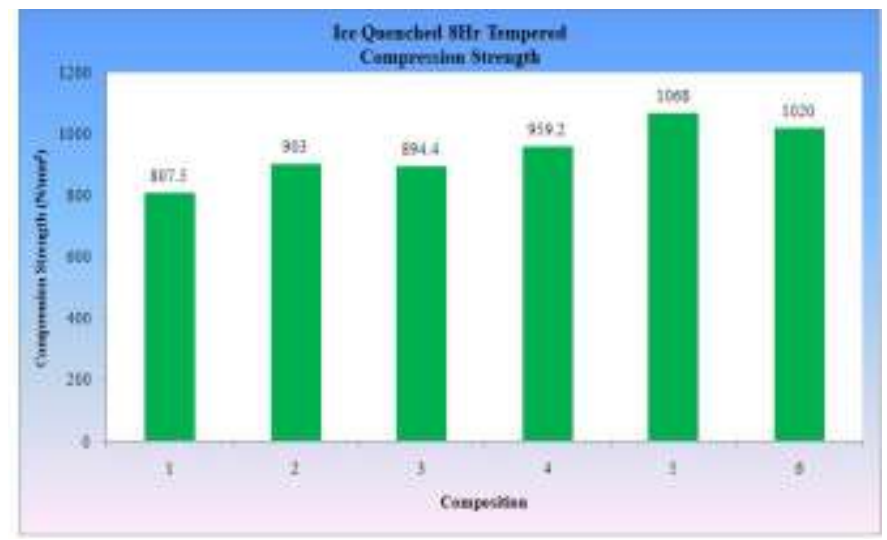

Fig 4.3.2 compression force of Ice Quenched 8Hr tempered Al LM13-Hematite

\section{CONCLUSION}

The conclusions written from the actual research are as follows:

1. The results verified that the Al alloy LM13 Reinforced with Hematite composite prepared by stir casting processes is clearly extraordinary to base $\mathrm{Al}$ alloy LM 13 in the resemblance of tensile strength, compression strength as well as Hardness.

2. Inclusion of Hematite particles in aluminium matrix increases the hardness of the composite matrix material.

3. It is identified that elongation will decrement with increment particles wt. percentage, which exactly shows that the Hematite inclusion increment brittleness.

4. Aluminium matrix composites is effectively manufactured by stir casting technology with gently uniform distribution of Hematite particles.

5. It shows that from the actual study that Ultimate Strength and Yield strength begins to grow with increment in weight percentage of Hematite particles in the matrix.

6 . The Increase in hardness takes place with increasing of Hematite particles in the matrix.

7. Results from the XRD indicate the presence Hematite particles in aluminium alloy matrix. The oxide phases like $\mathrm{A} 12 \mathrm{O} 3$ and $\mathrm{SiO}$ etc. have included homogenously entirely in the MMC thus strengthening the existing composite.

8. Compression strength is incremented by adding Hematite particles in the matrix material.
9. Stir casting process, stirring geometry of the apparatus, preheating temperature of the, particle inclusion rate etc. are the important parameters.

\section{ACKNOWLEDGEMENT}

My sincere thanks to my supervisors Meghani Molies reddy and Batluri Thilak Chandra for the valueable guidance offered during every stage of my research work.

\section{REFERENCES}

[1]. S. J. Harris, 1988, Cast Metal Matrix composites, Materials Science and Technology, Vol. 4, No 3, pp. 231239

[2]. S. V. Prasad and R. Asthana, 2004, Aluminum MetalMatrix Composites for Automotive Applications, Tribology letters, Vol. 17, No. 3, pp. 445-453.

[3]. N. Natarajan, S. Vijayarangan and I. Rajendran, 2006, Wear Behaviour of A356/25SiCpAluminium Matrix Composites Sliding against Automobile Friction Material," Wear, Vol. 261, No. 7-8, pp. 812-822.

[4]. S.Suresha, B.K.Sridhara, 2010, Effect of addition of graphite particulates on the wear behaviour in aluminium silicon carbidegraphite composites, Materials and Design, Vol 31, pp 1804-1812.

[5]. Yoshiro. Iwai, H. Yonede and T. Honda, 1995, Sliding Wear Behaviour of SiC Whisker-Reinforced Aluminum Composite," Wear, Vol. 181- 183, No. 2, pp. 594-602.

[6]. S. Basavarajappa and G. Chandramohan, "Wear Studies on Metal Matrix Composites: A Taguchi Approach,'Journal of Material Science Technology, , Vol. 21, No. 6, 2005, pp. $845-850$

[7]. N. Radhika, R. Subramanian and S. Venkat Prasat, "Tribologicalbehaviourof Aluminium/Alumina/Graphite Hybrid Metal Matrix

[8]. Composite Using Taguchi's Techniques," Journal of Minerals \& Materials Characterization \& Engineering, Vol. 10, No. 5, pp. 427-443, 2011.

[9]. World Academy of Science, Engineering and Technology International Journal of Environmental, Chemical, Ecological, Geological and Geophysical Engineering Vol:9, No:6, 2015683 International Scholarly and Scientific Research \& Innovation 9(6) 2015 scholar.waset.org/1999.6/10001549 International Science Index,

\section{BIOGRAPHIES}

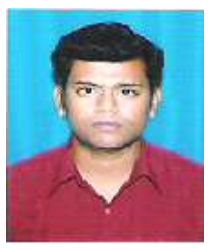

Rajesh $\mathbf{T} \quad \mathbf{R}$ working as a Assistant professor at GCEM Bangalore, Having a 3 years of experience in academics. Currently carrying out some research work.

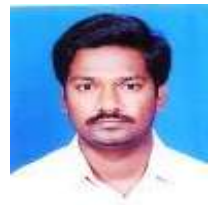

Meghani Molies Reddy working as a Assistant professor at SSIT Tumkur, Having a 6 years of experience in academics. Currently carrying out some research work. 


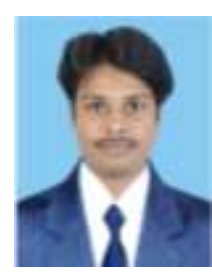

BatluriThilak Chandra working as a Assistant professor at SSIT Tumkur, Having a 6 years of experience in academics. Currently carrying out some research work on Development and tribological studies on PMMC for automotive applications

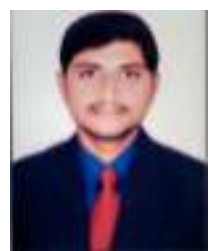

Sunil Kumar M working as a Assistant professor at PNSIT Bangalore, Having a 3 years of experience in academics. Currently carrying out some research work. 